\title{
Debate e Investigación Reconocer la cultura pesquera de la Antigüedad en Andalucía
}

Enrique Garcia Vargas. Universidad de Sevilla

Ángel Muñoz Vicente. Arqueólogo. Delegación Provincial de Cultura de Cádiz

\section{Resumen}

El presente trabajo aborda el estudio de la cultura y el patrimonio pesquero antiguos desde las perspectivas de su investigación, su conservación, su puesta en valor y su difusión. Se tratan en él aspectos fundamentales de la pesca maritima en el litoral andaluz durante la Protohistoria y la Edad Antigua, como son: Ios recursos pesqueros explotados, las técnicas y los aparejos de pesca empleados, la organización social de las pesquerias y las formas de conservación de los alimentos de base íctica. Finalmente, se atiende a la conservación, musealización y difusión de los restos materiales generados por la actividad pesquera durante la Antigüedad en la actual Andalucia , con especial incidencia en los más importantes: saladeros y alfares de ánforas para la exportación de las conservas de pescado.

\section{Palabras clave}

Patrimonio etnológico

Patrimonio pesquero

Pesca maritima

Técnica pesquera

Pesquerias

Pescadores

Saladeros

Salazón

Protohistoria

Edad Antigua

Artes de pesca

Andalucía

Conservas

Recursos pesqueros

\section{Introducción}

Son muchas las perspectivas desde las que puede abordarse el estudio del patrimonio pesquero legado por la Antigüedad; en las páginas que siguen nuestro interés se centrará, no obstante, en un único objetivo: poner de manifiesto la relevancia de la época llamada "antigua" como crisol de la cultura pesquera tradicional andaluza, una cultura enriquecida notablemente a lo largo de los tiempos posteriores, pero cuya "morfología" básica comienza a conformarse hace ya casi tres mil años. Todo ello, en el convencimiento de que reconocer el patrimonio pesquero andaluz pasa ineludiblemente por estudiar sus raíces, así como por conservar y poner en valor de cara a la sociedad los testimonios materiales de este legado.

\section{El cuento del pescador: recursos y dominios pesqueros del litoral andaluz}

En uno de sus Idilios, Teócrito, poeta siracusano del siglo III a. C., nos presenta a dos pescadores que antes del amanecer, momento en el que tendrán que reanudar el duro trabajo, y recostados aún en el interior de su mísera cabaña, comentan el sueño que uno de ellos, Asfalión, ha tenido durante la noche. En su sueño, Asfalión consigue con esfuerzo subir un gran pez hasta lo alto de la roca sobre la que se encuentra pescando y al ir a soltar el anzuelo descubre asombrado que aquello que acaba de pescar es un pez de oro (Id. 21.52).

El sueño de Asfalión es el del pescador de todos los tiempos: la gran pesca que lo libere, siquiera de forma transitoria, de los duros afanes de su oficio y de la mísera vida que proporcionan. Seguramente, haya que convenir con Th. Gallant en que, por lo común, ese sueño no ha sido nunca más que un fisherman's tale (Gallant, 1985) y en que, por lo mismo, la inmensa mayoría de los pescadores jamás ha tenido su pez de oro. Pero no es menos cierto que para un puñado de afortunados en unos cuantos tramos de costa especialmente favorecidos, el pez de oro se ha presentado durante siglos bajo la forma de inagotable cardumen de peces migradores de paso un par de veces al año por el litoral.

En el caso andaluz, esta gran pesca de pelágicos ha sido siempre abundante: atunes (Thunnus thynnus), bonitos (Sarda sarda), caballas (Scomber scombrus), estorninos (Scomber japonicus), melvas (Auxis rochei), bacoretas (Euthynnus alletteratus) y albacoras (Thunnus alalunga) penetran en primavera desde el Atlántico al Mediterráneo y, agrupados en grandes bancos que avanzan cerca de la superficie marina y a poca distancia de la costa, atraviesan el Estrecho para ser dispersados a la altura del Mar de Alborán por las turbulencias anticiclónicas de las corrientes marinas (Compán Vázquez, 1988: 212). A levante de la vertical Algeciras-Ceuta la densidad de las diversas especies de escómbridos, al menos de los de mayor tamaño, desciende, pues, considerablemente (Roselló Izquierdo y Morales Muñiz, 1988), hasta el punto de hacer menos rentable - e, incluso, desaconsejable - su pesca con grandes ingenios de cerco. 


\section{$044-045$ \\ Debate \\ e Investigación}

Reconocer la cultura

pesquera de la Antigüedad

en Andalucía

\section{PH44 - Julio 2003}

Sólo en el tramo levantino del litoral mediterráneo a partir de Adra, el régimen ciclónico local de las corrientes proporciona las condiciones para que los grandes escómbridos vuelvan a congregarse en cardúmenes de alguna densidad (Morales Muñiz y Roselló Izquierdo, 1988: 454). Pero esto es algo excepcional en la mayor parte de la costa mediterránea andaluza. Lo habitual en ella ha sido la captura de especies menores -sardinas (Sardina pilchardus), alachas (Sardinella aurita) y boquerones (Engraulis encrasicholus)-, de hábitat habitualmente demersal y de migraciones verticales en lugar de horizontales. Tanto un tipo como otro de desplazamientos son gaméticos (reproductivos), haciéndose los verticales al final del invierno (con un máximo secundario en otoño) desde el dominio bentónico o profundo al pelágico o superficial (Compán Vázquez, 1984: 212). En este momento, las diferencias de temperatura entre ambos dominios son poco notables debido al aumento general de la insolación y, sobre todo, al constante intercambio vertical de agua provocado por la irregularidad de los vientos y las frecuentes turbulencias marinas. La capa superficial recibe con ello un importante aporte de sales marinas fertilizantes, lo que hace aumentar considerablemente la masa de fitoplacton de que se alimentan los pequeños peces. Éstos ascienden a desovar desde las aguas profundas en las que hibernan, concentrándose especialmente en las costas de Estepona, y en las del poniente malagueño, donde las aguas profundas e intermedias cargadas de sales afloran gracias a los circuitos locales de contracorrientes marinas. Ello ha favorecido la especialización histórica de la costa malagueña en la captura de especies pequeñas (Otte, 1982: 223) como los engráulidos (boquerones: Engraulis encrasicholus) y los clupeidos (sardinas: Sardina pilchardus y alachas: Sardinella aurita), aunque no falten, como en el resto de los lugares de la costa, los espáridos -breca (Pagellus erythrinus), pargo (Pagrus pagrus), boga (Boops boops), etc.- , cuya versatilidad alimenticia y capacidad adaptativa los hace abundantes en casi cualquier ecosistema.
Se pueden, por tanto, señalar en el litoral andaluz, dos ámbitos pesqueros que a grandes rasgos vienen a coincidir respectivamente con los dominios atlántico y mediterráneo. En el primero de ellos, el atún (Thunnus thynnus) y el resto de los escómbridos migradores constituyeron desde muy antiguo los auténticos "peces de oro" que, como en el sueño de Asfalión, proporcionaron a sus captores riqueza y prosperidad durante años; en el segundo, algunos peces más modestos alcanzaron con el tiempo a ocupar este mismo papel, y aunque su cotización fue siempre más reducida, por su número y por la forma en que fueron procesados acabaron también convirtiéndose, al menos durante algún periodo, en un recurso importante para las poblaciones de la costa.

La diferenciación geográfica e hidrológica entre ambos sectores del litoral andaluz y la dedicación preferente a ictiofaunas diversas en casa uno de estos tramos resulta evidente para los tiempos protohistóricos a la vista de los análisis faunisticos realizados hasta el presente (Roselló Izquierdo y Morales Muñiz 1988; lidem, 1992, lidem, 1994 a; lidem, 1994 b; lidem, 1994 c; Morales Muñiz y Roselló Izquierdo, 1988; Rodríguez Santana, 1999). En estos estudios los yacimientos atlánticos (La Tiñosa, en Lepe; Cabezo de San Pedro y Puerto 10 en Huelva, y Castillo de Doña Blanca para una de sus fases, en la bahía de Cádiz) suelen estar representados por una fauna en la que son frecuentes los atunes rojos y las especies relacionadas con éstos en sus migraciones, especialmente los escualos; mientras que el atún está casi excluido (con la significativa excepción de Adra) de los yacimientos mediterráneos (como Toscanos, en Vélez-Málaga, o el Cerro del Villar, en Málaga) que presentan abundancia de taxones pequeños y medianos entre los que abundan los espáridos y, en lugares de explotación pesquera intensiva, como el Cerro del Villar (Rodríguez Santana, 1999), las especies de pescado "azul": clupeidos (sardinas: Sardina pilchardus) y engráulidos (boquerones: Engraulis encrasicholus).

\section{Voces}

\section{Industria conservera, pesca y patrimonio}

\section{Rafael Cáceres}

Autor del libro Mujeres, fábricas y charangas... ${ }^{1}$

A finales deI XIX, de la mano de industriales franceses e italianos, Ilegaron a España los nuevos procedimientos de conservación del pescado mediante el enlatado. Estos industriales instalaron las primeras fábricas de conservas, de forma casi simultánea, en Galicia, la costa cantábrica y el litoral atlántico andaluz. Fueron muchos los empresarios locales que atraidos por las buenas perspectivas de este negocio invirtieron en el nuevo sector, lo que originó que, ya a principios del siglo XX, en algunos pueblos andaluces la industria conservera se hubiera consolidado como la principal actividad. Este es el caso de Ayamonte e Isla Cristina, en la costa occidental de Huelva, donde un centenar de establecimientos industriales se convirtieron en el motor de la economía local hasta principios de los años setenta del siglo XX. El desarrollo conservero condicionó totalmente el resto de actividades de estos pueblos, la pesca quedó completamente subordinada a la industria conservera, desaparecieron la mayoria de las artes pesqueras tradicionales y, en su lugar, surgió una flota de embarcaciones de cerco dedicadas a la captura de sardinas y caballas para abastecer estas factorias.

El desarrollo del sector conservero configuró las estructuras urbanas de estos dos pueblos. La necesidad de ubicar las fábricas cerca de los lugares de descarga de pescado obligó al relleno de las riberas del Carreras en Isla Cristina y del Guardiana en Ayamonte para ganar terreno industrial. En las márgenes de estos ríos no sólo se levantaron embarcaderos de carga y descarga de mercancias sino, también, una gran cantidad de edificio industriales. Este es- 
De la época romana contamos con menor número de análisis ictiológicos. Tan sólo el caso de la factoría de salazones del Cerro del Mar (Torre del Mar, Málaga, muy cerca del yacimiento protohistórico de Toscanos) puede señalarse al respecto, indicando los estudios (von den Driesch 1980) que el atún, aunque se encuentra presente, no constituye la especie principal procesada aquí, pues es ampliamente superado en número por boquerones (Engraulis encrasicholus), sardinas (Sardina pilchardus) y, sobre todo, caballas (Scomber scombrus), estorninos (Scomber japonicus) y jureles (Trachurus trachurus), seguidos de diversas clases de espáridos -bogas (Boops boops), chuclas (Maena sp.), aligotes (Pagellus acarne), etc.

La escasez de análisis de ictiofaunas en lugares terrestres es compensado en este caso por los relativamente abundantes estudios acerca de los restos anatómicos de peces envasados en conserva dentro de ánforas de procedencia bética. Éstas fueron embarcadas para su exportación en las bodegas de barcos hundidos antes de alcanzar puerto y muestran tras su recuperación por parte de buceadores y arqueólogos modernos una cierta preferencia por las especies de pescado azul, en especial, escómbridos de tamaño intermedio, como puede observarse en la tabla 1 que recoge y sintetiza los datos aportados por diversos trabajos recientes (Delussu y Wilkens, 2000; Desse-Berset y Desse, 2000):

Por su parte, los tituli picti o rótulos pintados escritos sobre las ánforas y que, entre otros mensajes, llevaban la indicación de la clase de pescado utilizado en la elaboración de la conserva envasada en el recipiente (Martínez Maganto, 2001), señalan a menudo garum o liquamen scombri, lo que deja poco lugar a dudas de que se trató de salsas compuesta básicamente de caballas y coincide con la información de Plinio (Nat. 31.94) acerca de que este animal era empleado casi exclusivamente en la confección de salsas de pescado.
Un grupo relativamente numeroso de ánforas procedentes de diversos contextos del Mediterráneo occidental y de las provincias septentrionales del Imperio lleva, por su parte, como indicación de contenido el rótulo $\operatorname{cod}(. .$.$) o cord(...), abreviatura que, sobre la base de$ un texto archicitado de Plinio (Nat. 9.48), suele desarrollarse como co[r]dyla y cordyla, respectivamente, suponiendo que, como afirma Plinio, se trata de alevines de atún de menos de un año (Lequément, 1980: 259). La muestra de elementos de icticofauna en el interior de ánforas béticas estudiada hasta el presente es ciertamente escasa (tabla 1), pero la relativa frecuencia con que se encuentran representados los ejemplares de estorninos, o caballas del sur (Scomber japonicus), habitualmente completos y con las cabezas seccionadas por delante de las órbitas oculares para facilitar su desangrado, hace factible que sea en realidad este pez el que recibiera en la región en nombre de cordyla, dada la similitud de su aspecto anatómico con el de las crías de atún -de hecho, uno de los nombres que recibe en nuestras costas es el de tonino -. La cuestión no podrá resolverse, con todo, de manera definitiva hasta que tengamos la fortuna de encontrar un ánfora con indicación de contenido en el rótulo pintado y que a la vez contenga en su interior restos del esqueleto de los peces envasados en ella.

Un ánfora recuperada del pecio Gandolfo, en la costa de Almería (Liou y Rodriguez Almeida 2000) lleva la indicación Saxitani ue(teres) excel(lentes), que uno está tentado de relacionar con los coliae Saxitani o colias de Almuñécar (Sexi) mencionados por Plinio (Nat. 32.146). Aristóteles (HA, 8.15.6), fuente fundamental de Plinio en lo referido a la vida marina, señala claramente que el colias y el scomber son dos especies diferentes, siendo para Plinio el colias el menor de los representantes del genero de los lacerti, que englobaría a todos los "lagartos marinos", es decir, a aquellos peces cuyo tamaño y color es similar al de un lagarto (lacertus). Entre éstos, podemos señalar en el Mediterráneo la caballa (Scom- pacio se convirtió en una zona central en la que confluian las principales arterias de comunicación del pueblo. En los momentos de máxima actividad de la industria conservera se produjo una auténtica fiebre constructora, se construyeron un sin fin de edificios para albergar las fábricas de conservas y salazones. Si al principio se trataba de improvisados almacenes, a partir de los años veinte, comenzaron a planificarse construcciones funcionales, con instalaciones adecuadas a las actividades que se desarrollaban en su interior: fábricas de conservas, fábricas de salazones, charangas $^{2}$, carpinterias, talleres de embalses metálicos... El sector conservero no sólo generó una arquitectura industrial, sino que también propició que se levantara un gran número de viviendas tanto para obreros como para industriales. Dentro del primer grupo podemos encontrar los denominados brasiles, patios de vecinos, pertenecientes a empresarios conserveros, donde vivian los obreros de sus fábricas. Algunas de las casas de los industriales tenían como elemento característico una torre vigía de donde se divisaban las embarcaciones pesqueras a la entrada del puerto.
El patrimonio generado por el sector conservero no se limita exclusivamente a las industrias de conservas, sino que se extiende, como ya hemos visto, a la actividad pesquera. En la costa atlántica andaluza convergen embarcaciones y artes de pesca procedentes de diversos puntos del Mediterráneo y del Atlántico que se adaptaran a las condiciones de la zona y a las necesidades del sector industrial, dando lugar a un rico y variado patrimonio pesquero. Entre los múltiples barcos que durante años han faenado en estas aguas capturando sardinas para las fábricas de conservas cabe destacar los denominados galeones. Se trata de un barco procedente de aguas gallegas que se acondicionó para la pesca en estas latitudes, con redes de cerco de grandes dimensiones denominadas tarrafas.

La captura de sardinas y caballas para la industria conservera necesitaba también de instalaciones auxiliares. La llegada masiva de marineros-temporeros obligó a levantar una serie de viviendas colectivas donde alojar a estos trabajadores. Estas cons- 


\section{6 - 047 \\ Debate \\ e Investigación}

Reconocer la cultura

pesquera de la Antigüedad

en Andalucía

\section{PH44 - Julio 2003}

ber scombrus), el estornino (Scomber japonicus) y el jurel o "falsa caballa" (Trachurus trachurus); tal vez se refiera Plinio a estos últimos al hablar del colias Saxitanus, porque los jureles atrapados en las zonas cercanas a los puertos suelen ser crías y alevines. Desde luego, los del Pecio Sant-Gervais (tabla 1) son ejemplares adultos, no siendo éste probablemente el caso de los documentados en el Cerro del Mar (tabla 2). Marcial Ilama precisamente lacerti a los peces saxitanos (7.78), lo cual apunta de nuevo a una especie similar a la caballa, a la que siempre se denominó scomber.

Como quiera que sea, la evidencia ictioarqueológica, la epigrafía anfórica y la literatura antigua apuntan hacia el hecho de que a partir de los años iniciales de la era cristiana o poco antes, al compás de la "popularización" de los productos de pescado salado y del aumento general del nivel de vida, se sintió en el litoral bético una cierta preferencia por la pesca y el procesado de los escómbridos menores o especies similares -carángidos- con vistas a su exportación en forma de conserva (cf. Plin. Nat. 9.49). Estos peces son mayoritarios no sólo en la costa mediterránea, como evidencia el análisis de los restos de fauna recogidos en la factoría de salazones del Cerro del Mar, en Málaga (von den Driesch, 1980), sino también en la del Estrecho mismo, un litoral cuyas capturas "industriales" parecen haber estado hasta entonces dominadas por el atún. Plinio (Nat. 31.94) apunta este hecho al afirmar que las caballas (scombri) se pescan en Carteya, y el mismo fenómeno evidencian los rótulos pintados que indican que las cordylae envasadas en las ánforas son Ting(itanae) (de Tanger); Lix(itanae) (de Larache) y Port(uenses), o procedentes de un puerto que se ha identificado habitualmente con el de Cádiz.

El atún salado del Atlántico parece haber seguido teniendo, no obstante, una gran aceptación en todo el Mediterráneo en época romana (cf. Athen. 3.116; 3.118e), Ilegándose a nombrar explícitamente la salazón gaditana de atún (Galen. De alim. fac. 6.746K) y compare- ciendo este pez como tipo monetal en diversas cecas de la provincia entre la que destaca la de Gades, cuyas populares emisiones con atunes se remontan al siglo III a. C.) (Chaves Tristán y García Vargas, 1991). Sin embargo, el consumo del atún salado o, al menos, de sus partes escogidas (hipogastria o ventresca, homotarikos o mojama de lomo) no debió estar al alcance de todos (Garcia Vargas e.p. a; Idem, e. p. c), siendo tal vez envasadas en barriles o cajas de madera, lo que ha impedido que su tráfico comercial deje constancia arqueológica clara. Los restos de cabezas de atún troceadas del ánfora de Chiessi testimonian, no obstante, su transporte en contenedores cerámicos, así como el consumo de las partes menos suculentas del pez, como espinazos, cabezas y sangrazas (cf. Bresc 1985: 18-19 para el caso de las almadrabas sicilianas medievales).

A partir del siglo III d. C. en adelante, se aprecia un incremento notable en el procesado, comercio y consumo de especies aún más pequeñas que los escómbridos menores, como el boquerón (Engraulis encrasicholus) y la sardina (Sardina pilchardus), en detrimento de los escómbridos mayores y menores y también de los carángidos (tabla 2) a los cuales, al parecer, acabaron sustituyendo en su carácter de "peces de oro" del litoral sudhispano. Es posible que tras este fenómeno de auténtica "reconversión" de la pesca industrial desde las especies migradoras horizontales a las verticales se encuentren causas de tipo ecológico, como la sobreexplotación de los bancos de caballas y estorninos durante los siglos anteriores (Desse-Berset, 1993: 345) pero, tal vez, haya que considerar junto a esta explicación la existencia a partir de los años finales del siglo II d. C. de dificultades económicas importantes que impidieron la adecuada capitalización de las grandes artes pesqueras de cerco y arrastre, con su consiguiente sustitución por aparejos menos costosos, fenómeno que habria favorecido a las pesquerías del Mediterráneo andaluz y del Levante peninsular en general, así como a las del Atlántico portugués (García Vargas y Ferrer Albelda, 2001 a: 585ss; Garcia Vargas e. p. a). trucciones se denominan en Ayamonte patios y están formadas por habitaciones en torno a un estrecho patio. Estas estancias se utilizan tanto de viviendas como de almacenes de pertrechos de pesca. Junto a estas viviendas se levantan algunas construcciones como pozos, hornos y los llamados tinteros, donde se alquitranaban, para su mejor conservación, las enormes redes de pesca.

A partir de la década de los setenta la industria conservera entra en una profunda crisis de la que no logrará salir. En la actualidad, quedan en funcionamiento un par de fábricas en Isla Cristina y Ayamonte. Lógicamente, el declive de esta actividad económica ha ido acompañado de un progresivo deterioro del patrimonio industrial. A pasos agigantados se han derribado todo tipo de edificios vinculados a la actividad conservera. Sólo han corrido mejor suerte algunas construcciones que por su ubicación se han podido reutilizar como bares o tiendas. El desarrollo de turismo a partir de la década de los ochenta ha acelerado la desaparición de este pa- trimonio ya que el alto valor que adquiere el suelo en las zonas costeras contribuye a que no se respeten estas edificaciones.

Resulta llamativo que, mientras las autoridades locales han comenzado a reivindicar el patrimonio ligado a actividades económicas con muy poca tradición en la zona, como puede ser la agricultura, para ser utilizado con fines turisticos, existe un total desprecio por el patrimonio pesquero e industrial. Y es que las actividades industriales son consideradas,todavia "modernas" frente a otros sectores económicos, como la agricultura, que se ven como "tradicionales". ¿Para proteger el patrimonio pesquero e industrial debemos esperar a que ocurra lo mismo que con la agricultura? ¿Cuándo desaparezca totalmente comenzará el periodo de valoración y de "reinvención?" Muchos nos tememos que sea así.

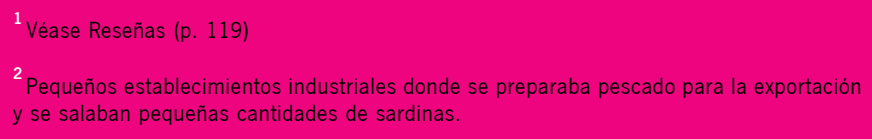


Tabla 1. Restos de fauna hallados en el interior de ánforas de procedencia bética (a partir de Deluss y Wilkens, 2000 y Desse-Berset y Desse, 2000)

\begin{tabular}{|c|c|c|c|c|c|}
\hline Pecio & Tipo de ánfora & Cronología & Especie de pez & Tamaño medio/pez & Producto \\
\hline Chiessi & Vindonissa 586 & Siglo I d. C. & Cabezas de Atún cortadas en trozos & & Salazón \\
\hline Elba & Tipo bético incierto & $2^{\mathrm{a}}$ mitad siglo I a $2^{\mathrm{a}}$ mitad s. II d. C. & Estorninos descabezados & En torno a $30 \mathrm{~cm}$ & Salazón \\
\hline Sud-Perduto II & Dressel 7 y Dressel 9 & Siglo I d. C. & Estorninos descabezados & Hasta $40 \mathrm{~cm}$ & Salazón \\
\hline Port-Vendres I & Vindonissa 586 & Mitad del Siglo I d. C. & Estorninos & & Salazón \\
\hline Sant-Gervais & Beltrán II B & Siglo II d. C. & Jureles & $40-50 \mathrm{~cm}$ & Salazón \\
\hline Cap-Bear III & Dressel 12 & Siglo I a. C. & Estorninos & $28-30 \mathrm{~cm}$ & Salazón \\
\hline Port-Vendres 1 & Keay XVI & 300-325 d. C. & Sardinas & $22-25 \mathrm{~cm}$ & Salazón \\
\hline Randello & Keay XVI & Principios del Siglo IV d. C. & Sardinas & $11-18 \mathrm{~cm}$ & Salazón \\
\hline Catalans & Keay XIX & Siglo IV d. C. & Escamas de Estornino & & Salsa \\
\hline Cabrera III & Beltrán 72 & Siglo III d. C. & Escamas de pescado indeterminado & & Salsa \\
\hline Sud Lavezzi 1 & Keay XIX & & Escamas de escómbrido & & Salsa \\
\hline
\end{tabular}

Tabla 2. Restos de fauna hallados en el interior de piletas de salazón de la Península Ibérica (a partir de von den Driesch, 1980; Roselló Izquierdo, 1989 y Desse-Berset y Desse, 2000)

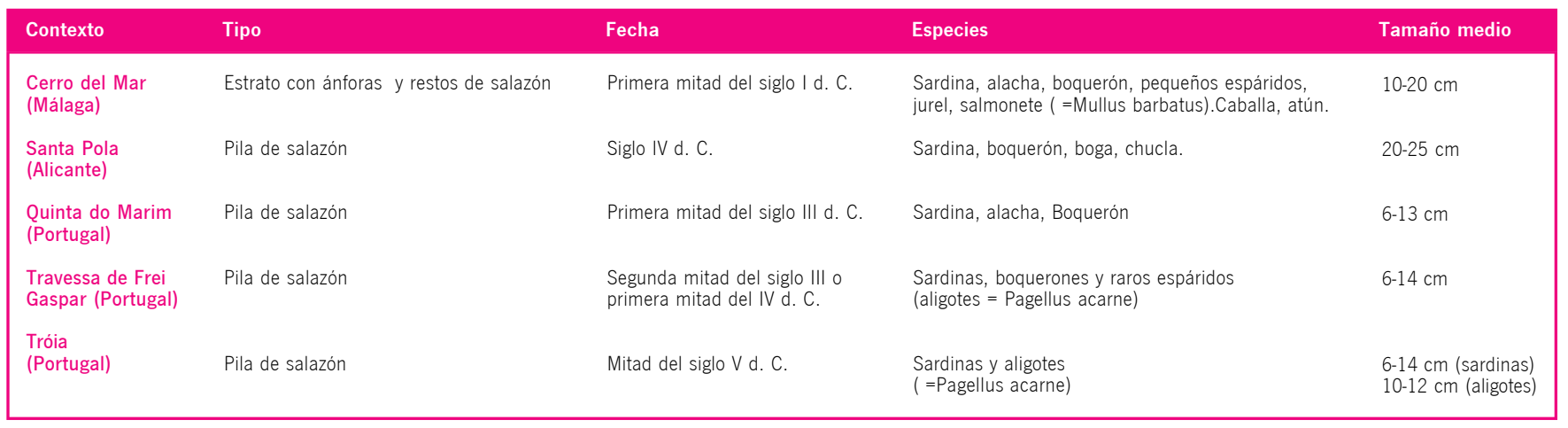

\section{Jardines en el mar: artes y aparejos}

Las diferencias hidrológicas y biológicas señaladas para los dominios marítimos atlántico y mediterráneo debieron, sin duda, reflejarse en el empleo predominante de artes de pesca diferentes a ambos lados del Estrecho, al menos, hasta la relativa unificación de prácticas pesqueras que debió suponer la exportación masiva de escómbridos menores y carángidos a partir de época altoimperial romana (supra). El hecho de que los aparejos pesqueros se confeccionasen en la Antigüedad con materiales perecederos nos priva, sin embargo, de una importante fuente de información -la arqueológica- al respecto de las técnicas de pesca en el litoral andaluz durante la Antigüedad (García Vargas, 2001: 14). El estudio y sistematización de los elementos metálicos y líticos de las artes de red, especialmente de los pesos de plomo o piedra que han perdurado a lo largo del tiempo y que son relativamente frecuentes en los yacimientos costeros andaluces, puede arrojar luz, junto al de los anzuelos y los diversos tipos de agujas metálicas, acerca del tamaño de las artes y el tipo de capturas al que se dedicaron, pero lo cierto es, que el estudio de esta clase de materiales se encuentra aún poco desarrollado (Ribeiro, 1970; Gracia Alonso, 1981-82; Feugère, 1992; Martínez Maganto, 1992), al menos en Europa Occidental (cf. Galili et al. 2002, para las costas de Israel) y no carece en el fondo de serias limitaciones derivadas de su escasa variedad tipológica y funcional.

La literatura clásica (Aristóteles, Opiano, Eliano, Filóstrato y Plinio, en especial) y la iconografía antigua de tema marino en pinturas y mosaicos (Pekáry, 1999; Bekker-Nielsen, 2002: passim) son sin duda fundamentales para conocer las técnicas de pesca más corrientes en la Antigüedad, pero el tono poético y moralizante general de las primeras y el carácter estereotipado de las segundas, en torno a composiciones idealizadas de tema nilótico y origen helenístico (Foucher, 1965), las hace poco útiles para descender al detalle necesario en un estudio de tipo regional. Tan sólo un análisis detenido de las especies documentadas en los yacimientos andaluces que contemple las tallas medias de los ejemplares capturados y las asociaciones de especies en cada lugar puede arrojar luz, combinado con otros datos arqueológicos y literarios, acerca de los aparejos empleados en la pesca de cada una de ellas.

Los análisis realizados en lugares como el Cerro del Villar (Málaga) para época protohistórica concluyen tras el estudio de estas variables que las redes con luz de malla reducida debieron ser habituales en la costa malagueña desde los inicios casi de la presencia fenicia en la zona (Rodríguez Santana, 1999: 323), algo bien diferente al caso contemporáneo del Castillo de Doña Blanca, en la bahía de Cádiz, donde sobre la base del estudio de los mismos factores, se propone para las mismas fechas (siglo VIII a. C.) (Roselló Izquierdo y Morales Muñiz, 1994 a 122) un empleo casi exclusivo de artes selectivas de pesca centradas en el empleo del anzuelo. Factores culturales, geográficos y bio-hidrológicos deben considerarse como determinantes a la hora de provocar esta diferenciación regional que ya señalábamos al principio de estas líneas como característica de la pesca protohistórica andaluza; pero lo que nos interesa ahora es señalar que desde los inicios de la pesca a escala amplia puede señalarse el empleo de artes diversas centradas respectivamente en el uso del anzuelo y de redes de luz de malla y de tamaño diversos - aunque deben mencionarse también para ésta época y la posterior otros tipos de pesca menos productivos como las que emplean los llamados "corrales" (Moreno Páramo y Abad Casal, 1978) o las que usan de otros instrumentos como el tridente (García Vargas, 2001: 16)artes que serán empleadas también en época romana 


\section{$048-049$ \\ Debate e Investigación \\ Reconocer la cultura pesquera de la Antigüedad en Andalucía \\ PH44 - Julio 2003}

La pesca con línea y anzuelo no es necesariamente poco productiva. Habitualmente se asocia a la figura del pescador solitario, como el representado en las monedas de Carteya, cuyo trabajo apenas alcanza a procurarle el sustento (Fig. 1); se olvida a menudo el rédito que ofrece el empleo de líneas de múltiples anzuelos, conocidas en nuestras costas como palangres que, arrojadas por los pescadores ordenadamente para evitar que se enreden entre si desde ambas bordas de las embarcaciones (cf. Merino 1990), suelen procurar abundante pesca, dependiendo las especies capturadas con ellos de la profundidad a la que se calen, del tamaño de los anzuelos y del tipo de cebo empleado. Los palangres dedicados a los grandes escómbridos - las actuales marrajeras -, en los que quedarian, sin duda, enganchados también los escualos cuyos restos se documentan en los yacimientos atlánticos protohistóricos (supra), debieron ser de uso habitual entre los pescadores gaditanos que, según el ps.Aristóteles (Mir. 136a) se aventuraban en el banco pesquero sahariano (Mederos y Escribano, 1999) en frágiles naves llamadas hippoi (Luzón Nogué, 1988); Opiano, que vivió entre los siglos II y III d. C., los Ilama (Hal. 3.78) polyankístroi y Caudio Eliano, contemporáneo de éste, (N.A. 15.10) describe la pesca de pelámides - posiblemente bonitos (Sarda sarda) - con líneas anzueladas arrojadas desde la borda de embarcaciones y dotadas en cada anzuelo con plumas de gaviota y trozos de lana púrpura que atraían la pesca con su forma y movimiento. El ingenio que describe Eliano y del que dice que procuraba una "muchedumbre de peces", recuerda mucho al descrito a fines del siglo XVIII por Sáñez Reguart bajo el nombre de "bonitolera", un palangre de bonitos que constaba de parejas de anzuelos dotados de plumas de ave (Sáñez Reguart, 1791: vol I, p. 298, lam. XLVI).

Pero la productividad de los palangres, sin ser despreciable, tal vez no alcanzara a proveer a los saladeros de la costa con tantas capturas como éstos eran capaces de procesar (Garcia Vargas, 2001: 16). La pesca del atún y de otros escómbridos medianos como el bonito (Sarda sarda) o la melva (Auxis rochei) es mucho más rentable con artes de cerco y arrastre desde la playa como la atunara o almadraba. Ésta aprovecha el avance migratorio de los cardúmenes de peces, que avanzan aproximadamente en paralelo a la costa, para interceptar su paso y proceder a capturarlos por centenares.

En contra de lo que normalmente se cree (Martínez Maganto, 1992: 236-7), las almadrabas de cuadro fijo - bien de buche, más simple, bien de monteleva, más compleja - no han encontrado aceptación en las costas andaluzas hasta bien entrado el siglo XIX. Su origen es más antiguo, desde luego, pues se remontan al menos al siglo IX d. C., siendo al parecer una invención de los pescadores bizantinos de la zona de los estrechos del mar de Mármara (Dagron, 1995: 64), área geográfica tan rica en grandes escómbridos como la del Estrecho de Gibraltar. La primera mención de su empleo se hace en la legislación del emperador León VI (Novela LVII), quien decreta la propiedad privada de las aguas inmediatas a los dominios pesqueros en favor de los dueños de los mismos. La ausencia de prescripciones similares en el Derecho anterior, que consideró siempre las aguas del mar como res communis, fue explicada por el legislador como una consecuencia de la inexistencia de las redes de cuadro fijo, que de-
Fig. 1. El pescador solitario: Kylix del pintor de Ambrosios, aprox. 480 a. C. (según Donati y Pasini, 1997)

Fig. 2. Jábega (según la Enciclopedia de Diderot y D'Alembert)

Fig. 3. Cuatro sistemas de pesca en un mosaico de Susa, Túnez ( según Donati y Pasini, 1997)

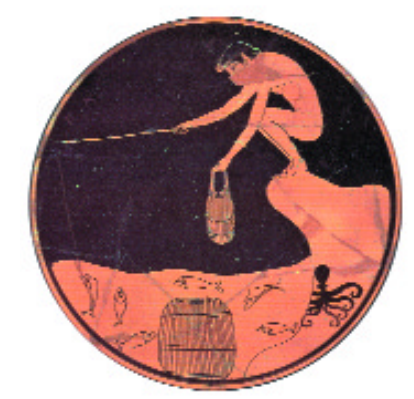

nomina épokai, con anterioridad a su época; el nombre mismo de époke (e)pokh \o retención) se buscará en vano en la literatura griega anterior al siglo IX d. C.

Las almadrabas habituales hasta tiempos recientes en las costas andaluzas han sido, por el contrario, las de vista o tiro (sobre las cuales, cf. para la Antigüedad: Eliano, N. A. XV.5; Opiano, Hal. 3.638ss; Filóstrato, Im. 1.13.9; Manilio, Astr. 5.667-8; Mastromarco, 1998; Fernández Nieto, 2002: 242 ss.); lanzadas por varias barcas y de las que se halaba desde la playa. El semicírculo que crean sus redes concéntricas, de las que la situada en el interior contenía el copo, se ha llamado tradicionalmente "jardin", un "jardín" que guardaba en su seno toda la inmensa riqueza que la pesca de escómbridos proporcionaba a las poblaciones del litoral.

La jábega o xâbiga (Fig. 2 )es una versión reducida de la almadraba de tiro y como ésta recibía en la Antigüedad el nombre genérico de sagena, aunque en latín era también denominada uerriculum o tragula (Seruius Honorat. 1.59). Las jábegas se halan, como las almadrabas, desde la playa, una vez que los barcos calones han lanzado el aparejo y han llevado a tierra los cabos terminales (Sáñez Reguart, 1791: t. V, p. 359) aunque en ocasiones, como resulta evidente a la vista de las representaciones figuradas de los mosaicos (Pekáry, 1999; Bekker-Nielssen, 2002), redes similares a las jábegas podía manejarse dentro del mar desde uno o dos barcos (Fig. 3). Las jábegas se han usado tradicionalmente en el litoral mediterráneo de Andalucia, y también en el del Atlántico, para la pesca de especies menores, especialmente el boquerón (Engraulis encrosicholus) y la sardina (Sardina pilchardus) (Delgado Domínguez, 2001: 85).

Al contrario que almadrabas y jábegas, los trasmallos (Fig. 4) son artes fijas de red, aunque uno de sus extremos puede dejarse a la deriva. Se trata de grandes lienzos que suelen constar de más de un paño de red en los que los peces, que tropiezan en ellos como en una cortina que les intercepta el paso, quedan embolsados; la profundidad de los trasmallos puede regularse con pesos en la relinga de plomos y flotadores en la de corchos, de modo que actúan también, anclados con pesos de piedra, como artes de superficie aptas para la pesca de especies migradoras. Es posible que alguna de las piedras horadadas que se han hallado en prospecciones submarinas en las costas andaluzas (Blánquez et al., 1997 ) y que suelen relacionarse con anclas de tipología arcaica, sean en realidad pesos de fijación de trasmallos o artes semejantes (Garcia Vargas, e. p. a), si no se trata en ocasiones de "anclas" para nasas (García Vargas, e. p. b). Una versión simple del trasmallo, llamada piquera, que consta de un solo lienzo y en el que los peces quedan atrapados por el opérculo, parece ser descrita por Opiano (Hal. 3.80) al respecto de la pesca de la caballa. Tal vez el empleo de este tipo de artes sea la causa de la homogeneidad de los tamaños de caballas (Scomber scombrus), estorninos (Scomber japónicus), jureles (Trachurus trachurus) y sardinas (Sardina pilchardus) en las ánforas (tabla 1) y las chancas de salazón antiguas (tabla 2), pues, si no hubo una selección de tamaños posterior a la captura, puede suponerse que anchos de malla homogéneos en las piqueras sólo pescaban ejemplares de tamaño similar. 


\section{$050-051$ \\ Debate \\ e Investigación}

Reconocer la cultura

pesquera de la Antigüedad

en Andalucía

\section{PH44 - Julio 2003}

2001) y considerable el de las catalogadas en época romana (Lagóstena Barrios, 2001). Los productos de los saladeros andaluces tuvieron una gran aceptación en todo el Mediterráneo desde al menos el siglo V a. C. (Frutos Reyes y Muñoz Vicente, 1996; Garcia Vargas y Ferrer Albelda, 2001b), siendo envasados y expedidos por vía maritima hasta la antigüedad tardía en ánforas muchos de cuyos hornos se han excavado y catalogado en todo el litoral de la región.

Factorias de salazón y alfares de ánforas salsarias constituyen hoy día lo más visible del patrimonio pesquero antiguo de Andalucía, habiéndose realizado en los últimos años un gran esfuerzo de investigación, conservación y puesta en valor de los mismos, labor cuyas líneas generales sintetizamos en el apartado siguiente sobre la base de un ejemplo concreto: el de la provincia de Cádiz.

\section{La conservación del patrimonio arqueológico pesquero en Cádiz}

El patrimonio pesquero de la Antigüedad no es extraño a estas reflexiones. Su conservación debe partir de un análisis previo y riguroso de las posibilidades de su interpretación como resultado de los procesos investigadores. Esta realidad que nos proporciona el investigar o el simple legado ya exhumado total o parcialmente que nos ha transmitido el pasado, aconseja en un principio establecer una diferenciación entre patrimonio pesquero en medio urbano y patrimonio pesquero en medio rural. Las especiales caracteristicas y circunstancias de ambos medios definirán las distintas posibilidades de exposición, lectura y sistemas de conservación bien desde la óptica difusora, bien desde la protectora.

La lectura de las factorías de salazones de la ciudad romana de Baelo Claudia (Fig. 7), por ejemplo (ámbito rural), no necesita para su comprensión, un mayor esfuerzo de musealización, pues su ubicación y relación con el resto del yacimiento (la ciudad) explican por si solas y con la suficiente claridad la función y razón de ser de este asentamiento. En este caso, las actuaciones de conservación y mantenimiento de las estructuras tendrán una clara preponderancia sobre las actividades de difusión.

En cambio, la musealización de un sector de una factoría de salazones de Gades (la actual Cádiz), conservada en una parte de un sótano de un edificio en pleno centro antiguo de la ciudad, necesitará de un mayor esfuerzo expositivo y de difusión, pues se nos presenta como un elemento aislado, encajonado entre paredes de hormigón, en un paisaje muy diferente al que tuvo la zona durante la Antigüedad, en la actualidad muy alejada del mar. Aquí la difusión debe adquirir un papel preponderante frente a la conservación, pues por muchas actividades conservacionistas que se proyecten 0 desarrollen en el bien, no podrá ser legible y comprendido, sino se articula en un discurso expositivo coherente y suficientemente amplio que lo relacione con el resto de la ciudad antigua y lo integre en su paleopaisaje.
Fig. 4. Trasmallo (según la Enciclopedia de Diderot y D'Alembert) Fig. 5. Vendedor de pescado siglo IV a. C. en una crátera siciliota de Cefalù (según Donati y Pasini, 1997)

Otro aspecto a considerar sobre el patrimonio pesquero en la Antigüedad es el de no agotar su potencial arqueológico, mediante la creación y delimitación de zonas de reservas de acuerdo con las categorias de protección definidas en la Ley 1/91 de 3 de julio, de Patrimonio Histórico de Andalucía y su desarrollo reglamentario, el Decreto 19/95, de 7 de febrero de Reglamento de Protección y Fomento del Patrimonio Histórico de Andalucia.

A veces, ciertos sectores sociales, reunidos en torno a asociaciones ecologistas 0 , incluso, al amparo de denominaciones de salvaguarda del Patrimonio Histórico o Arqueológico, demandan de la administración competente la excavación y puesta en valor de yacimientos, simplemente por razón de cualquier hallazgo casual, como supuesta medida contra el expolio o como el medio para evitar la erosión por distintos agentes.

Este es el caso del yacimiento pesquero de época romana de la Ensenada de Valdevaqueros en Tarifa (Cádiz), muy próximo a Baelo Claudia, sometido durante los meses estivales a una fuerte presión por la acción del hombre que utiliza los terrenos donde se ubica el yacimiento, de titularidad privada, como zona de acampada y aparcamiento. Este enclave, constituido por una factoría de salazones, conocido erróneamente por la historiografía reciente como "ruinas de Mellaria" (Alonso Villalobos y García Vargas, 2003) permanece sin excavar y sin prácticamente estructuras visibles. Tan sólo, las cabeceras de algunos tramos de muros se dibujan sobre la actual superficie y otros seccionados asoman por el pequeño talud que da a la playa.

Las demandas de estos grupos de excavaciones en extensión y su acondicionamiento para la visita pública son habituales desde hace más de veinte años.

Todas estas circunstancias de este yacimiento conservado gracias a permanecer enterrado desde su abandono en plena época romana, desaconsejan el desarrollo de un proyecto de excavación y musealización, sobre todo, si tenemos en cuenta que los factores de degradación que lo amenazan, no son solucionables a corto plazo. Asimismo, la proximidad de las factorías de Baelo Claudia, que por sí solas explican el patrimonio pesquero romano en este sector de la costa atlántica gaditana, es otro factor a tener en cuenta en este sentido. Resulta absurdo en las actuales circunstancias, desdoblar esfuerzos de conservación difusora en yacimientos con estas caracteristicas. Más bien, lo adecuado sería dotarlo de medidas de conservación proteccionistas, tales como el disponer sobre su superficie una capa de tierra que lo proteja (enterrar el yacimiento enterrado), del uso agresivo a que se ve sometido y establecer en consecuencia una zona de reserva para la investigación futura.

Si estas reflexiones generales podemos hacerlas extensivas a los numerosos yacimientos romanos dedicados a la elaboración de productos derivados de la pesca, existentes en las costas andaluzas, cuando nos referimos al patrimonio pesquero de época feniciopúnica, los ejemplos podemos reducirlos a la provincia gaditana y, más concretamente, a la Bahía de Cádiz. Este ámbito territorial en 


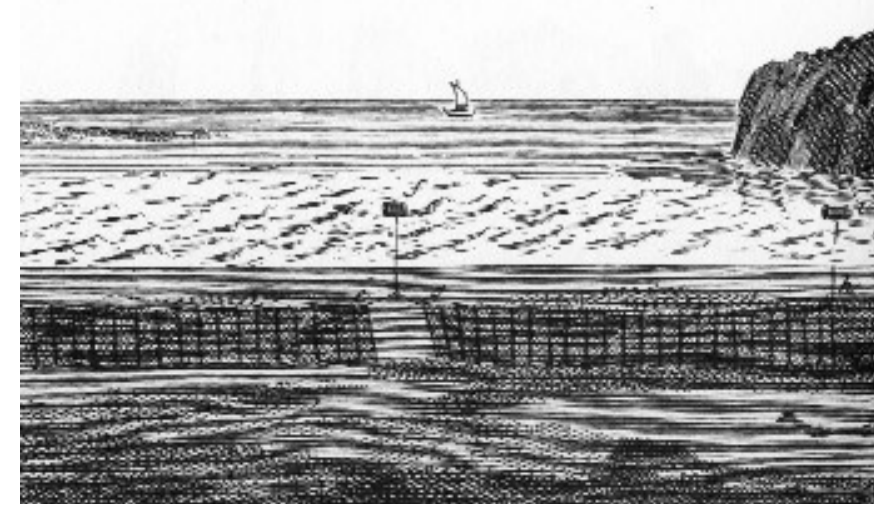

el actual estado de la investigación se configura como el eje vertebrador de los referentes industriales pesqueros en un marco cronológico que abarca desde el último cuarto del siglo VI a.C. hasta la implantación del sistema económico romano. Es en esta zona donde los productos derivados del mar adquieren desde los primeros momentos un claro matiz industrial y pasan a ser una alternativa comercial al colapso del mercado de otros productos como la plata o el estaño, en clara regresión en cuanto a su cotización en los circuitos comerciales internacionales.

Estos datos cobran especial importancia si tenemos en cuenta que tan sólo han sido dados a conocer al mundo científico, además de los ejemplos pesqueros gaditanos, dos enclaves de salazones más en todo el Mediterráneo, uno en San Vito, en la Sicilia Occidental y otro a los pies del Monte Cofano en la misma isla, de los siglos IV y III a.C., mientras que el resto de las industrias que debieron jalonarse por las costas atlánticas y mediterráneas permanecen sin excavar y publicar.

Dentro de la Bahía gaditana, las factorias de salazones se distribuyen por las costas de los municipios de El Puerto de Santa María y de la propia Cádiz, mientras que los alfares, dedicados a la elaboración de los contenedores para el transporte de salsas y salazones, se ubican en la línea costera del interior de la Bahía, y casi con exclusividad en el término de San Fernando.

Las factorías excavadas, dos en El Puerto de Santa María (Las Redes en 1980 y Pinar Hondo en 1986) y otras dos en Cádiz (Plaza de Asdrúbal en 1985 y Av. De Andalucía / ciudad de Santander en 1986), fueron fruto de actividades arqueológicas de urgencia, generadas por proyectos constructivos de nueva planta y por tanto marcadas desde el principio a su desaparición tras los respectivos procesos de investigación. De ellas, tan sólo la de Las Redes, por su aceptable estado de conservación y disponer de la totalidad de su planta y estructura interna, podría haber sido objeto de algún tipo de propuesta de conservación. Sin embargo, en el año en que fue excavada, en 1980, en los albores del nacimiento de la denominada arqueología de gestión, y cuando aún no se habían publicado la Ley de Patrimonio Histórico Español de 1985, el conseguir que se excavase en su totalidad, fue ya un logro para el mundo científico.

Sin embargo, posteriores trabajos de prospección superficial en este sector de la costa atlántica gaditana, determinaron la existencia de al menos veinte enclaves similares. Desde su descubrimiento, allá por 1986, se vio la necesidad de establecer mecanismos encaminados a su protección desde el punto de vista legal. A tal fin se inició la redacción del documento para su declaración como Bien de Interés Cultural. Diversas circunstancias de oportunidad, prioridad y otras cuestiones como un ámbito a proteger excesivamente amplio y un gran número de titulares del derecho de propiedad afectados por el expediente, hicieron que al día de hoy estos yacimientos permanezcan aún sin incoar.

La protección de estos yacimientos, al igual que sucede con la inmensa mayoría de ellos, se ha derivado hacia la normativa urbanís-

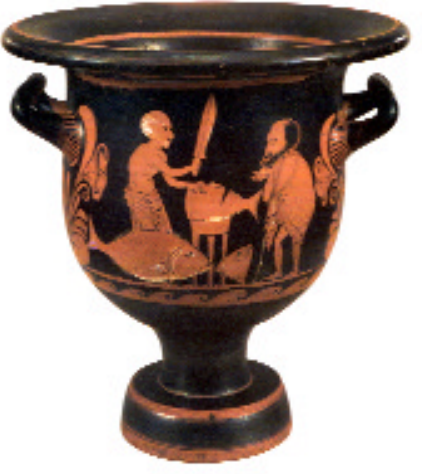

tica, ya que es de donde provienen los mayores factores de pérdidas de este Patrimonio, de forma que puedan evitarse con medidas dentro de la propia norma que rige el uso del suelo.

En la actualidad las factorias de salazones portuenses de época fenicio-púnica se encuentran incluidas en el catálogo de elementos del Patrimonio Arqueológico del Plan General Municipal de Ordenación de la localidad, actualmente en revisión.

En el otro plato de la balanza podemos situar el patrimonio alfarero dedicado a la elaboración de los contenedores (ánforas) destinados al transporte y comercialización de los productos derivados de la pesca. Es de destacar, en 1988, la localización y excavación de dos hornos de finales del siglo III a.C. a primeros decenios del siglo II a.C. en el yacimiento de Torre Alta, en San Fernando (Cádiz), con un estado de conservación medio, que condicionaron el trazado urbanístico de los estudios que se estaban realizando sobre la zona. La oportunidad de su conservación "in situ", Ilevó a proyectar para su salvaguarda una rotonda ovalada, atípica, hiperdimensionada con relación a los viales y poco operativa desde el punto de vista del tráfico rodado. Sin embargo, y esto es desgraciadamente un ejemplo poco común en nuestros días, donde la disciplina urbanística impera por doquier sobre cualquier otra demanda es en la valoración de estas estructuras, aún cuando carecen de monumentalidad, ya que se trata de simples elementos funcionales de corte industrial que llevaron a los responsables municipales por aquel entonces a no dudar en su conservación y adecuar y supeditar el desarrollo urbano de esa zona a las necesidades planteadas por los descubrimientos arqueológicos.

Con el paso de los años esta rotonda ha recibido nuevos elementos patrimoniales pesqueros de la misma funcionalidad. En 1998 tras la excavación de los hornos fenicios del Sector 3 de Camposoto, también en San Fernando, se determinó la idoneidad de su traslado a esta área de Torre Alta, de manera que en un único territorio pudieran visualizarse y comprenderse este sector industrial pesquero destinado a la fabricación de los contenedores para el transporte de sus productos.

A fines de abril de 2003, el proyecto de musealización de este complejo alfarero gaditano de época fenicio-púnica está terminándose. Cuando este texto vea la luz, será una realidad, que ha recorrido un largo y dificil camino ante la incomprensión y críticas de algunos sectores sociales. Sin embargo, el esfuerzo, de la administración local y autonómica, ha merecido la pena. La denominada plaza de los Hornos Púnicos de San Fernando es hoy día un referente único en el ámbito internacional para el estudio y disfrute de un sector industrial que caracterizó a la Bahía de Cádiz durante toda la Antigüedad.

Estos ejemplos gaditanos expresan con claridad que cualquier propuesta de conservación requiere de estudios pormenorizados y particularizados, en donde las propias características del elemento o los elementos a musealizar y sus relaciones con el entorno, serán determinantes para adoptar la solución más idónea y conseguir trasladar este patrimonio a las generaciones venideras. Conservar para proteger es sin duda un paso más para difundir. 
$052-053$

\section{Debate}

e Investigación

Reconocer la cultura

pesquera de la Antigüedad

en Andalucía

PH44 - Julio 2003

\section{Bibliografía}

ALONSO VILLALOBOS, C. y GARCíA VARGAS, E. (2003) Geopolitica imperial romana en el Estrecho de Gibraltar: el análisis geoarqueológico del puerto de Baelo Claudia y el emplazamiento de Mellaria. Habis, Tarifa, Cádiz: $n^{0}$ 34, 2003, pp. 187-200

AUBET SEMLER, Ma . E. (1993) Cerro del Villar (Guadalhorce, Málaga). El asentamiento fenicio y su interacción con el hinterland. Investigaciones Arqueológicas en Andalucia, 1985-1992. Proyectos. Huelva: Junta de Andalucía, 1993, pp. 471 479 .

BEKKER-NIELSEN, T. (2002) Nets, boats and fishing in the Roman world. [En linea], Copenhague: 2002. <http://www.pontos.dk/e_pub/TBNNets.htm> [consulta 28/04/2003]

BLÁNQUEZ, J.; ROLDÁN, L.; MARTÍNEZ LILLO, S.; MARTÍNEZ MAGANTO; J., SÁEZ, F.; BERNAL, D. (1997) La carta arqueológica subacuática de la costa de Almería (1983-1992). Sevilla: Consejería de Cultura, Junta de Andalucía, 1997

BRESC, H. (1985) La pêche et les mandragues dans la Sicilie médiévale. L'homme méditeranéen et la mer. Actes du Toisième Congrés International d'Études des Cultures de la Méditerranée Occidentales. Jerba 1981, Túnez: v. 2, 1985, pp. 13-26

CHAVES TRISTÁN, F.; GARCíA VARGAS, E. (1991) Reflexiones en torno al área comercial de Gades. Estudio numismático y arqueológico. Gerión. Homenaje al Dr. Michel Ponsich, 1991, pp. 139-168

COMPÁN VÁZQUEZ, D. (1984) La pesca maritima en Andalucia. En CANO GARCíA, G. (ed.). Geografía de Andalucía. Sevilla: Ediciones Tartessos, v. 5, 1984, pp. 201-279

CURTIS, R. I. (1979) The production and Commerce of fish sauce in the western Roman Empire: a social and economic study. Ann Arbor (Mi): University Microfilm International, 1979.

CURTIS, R. I. (1991) Garum and salsamenta: production and commerce in materia medica. Londres, Nueva York, Copenhague, Colonia: Studies in ancient Medicine, 1991

DAGRON, G. (1995) Poissons, Pêcheurs et poissoniers de Constantinople. En MANGO, C. y DAGRON, C (eds.). Constantinople and its hinterland. Papers from the 27th Spring Symposium of Bizantine Sudies. Oxford, April 1993. Oxford: 1995, pp. 57-73

DELGADO DOMínGUEZ, A. (2001) Pesca y producción de conservas de pescado en época antigua en el litoral onubense. Estado de la cuestión (s. IV a. C. - IV d. C.) Memoria de Licenciatura dirigida por los Drs. G. de Frutos Reyes y G. Chic Garcia, Universidad de Huelva, 2001. Facultad de Humanidades, Biblioteca.

DELUSSU, F. y WILKENS, B. (2000) Le conserve di pesce. Alcuni dati da contesti italiani. MEFRA : Mélanges de l'École Française de Rome. Antiquité, $n^{0} 112$, 2000, pp. 53-65

DESSE-BERSET, N. (1993) Contenus d'amphores et surpêche : l'exemple de Sud-Perduto (Bouches de Bonifacio). En DESSE, J. y AUDOIN-ROUZEAU, F. (eds.). Exploitation des animaux sauvages à travers les temps. XIIle Rencontres Internationales d'archéologie et d'histoire d'Antibes : actes des rencontres 15-16-17 octobre 1992, Juan-les-Pins, 1993, pp. 341-346
DESSE-BERSET, N. ; DESSE, J. (2000) Salsamenta, garum et autres preparations de poissons. Ce qu'en dissent les os. MEFRA : Mélanges de l'École Française de Rome. Antiquité, nº 112, 2000, pp. 73-97

DONATI, A. ; PASINI, P. (dirs.) (1997) Pesca e pescatori nella antichità. Milán Elemond Editori Associati. Roma, 1997.

DRIESCH, A. (1980) von den, Osteoarchäologische Auswertung von Garum Resten des Cerro del Mar. MM: Madrider Mitteilungen , n² 21, 1980, pp. 151-154.

DUMONT, J. (1976-1977) La pêche du thon à Byzance a l'époque hellénistique. REA: Revue des Études Anciennes, LXXVIII-LXXIX, 1976-1977, pp. 96-119.

FERNÁNDEZ NIETO, F. (2002) Hemeroskopeion=Thynoskopeion. El final de un problema histórico mal enfocado. Mainake. Tema monográfico: Colonizadores e indigenas en la Península Ibérica. Málaga: Centro e Ediciones de la Diputación de Málaga, 2002, pp. 231-255.

FEUGÈRE, M. (1992) Les instruments de chasse, de pêche et d'agriculture. Lattara, $n^{0} 5,1992$, pp. 139-162

FOUCHER, L. (1965) Les mosaiques nilotiques africaines. Colloque International sur le Mosaïque Greco-romaine. Paris, 29 Août- 3 Septembre 1963. París: CNRS, 1965: 137-145

FRUTOS REYES, G.; MUÑOZ VICENTE, A. (1996) La industria pesquera y conservera púnico-gaditana: balance de la investigación, Nuevas perspectivas. Spal. Revista de Prehistoria y Arqueología. Universidad de Sevilla, n 5, 1996, pp. 133-165

GALILI, E.; ROSEN, B.; SHARVIT, J. (2002) Fishing-gear sinkers recovered from an underwater wreckage site, off the Carmel coast, Israel. The International Journal of Nautical Archaeology, n³ 31.2, 2002, pp. 182-201

GALLANT, T. W. (1985) A Fisherman's Tale: an Analysis of the Potential Productivity of Fishing in the Ancient World. Gante: Miscelanea Graeca, fasciculus 7, 1985

GARCÍA VARGAS, E. (2001) Pesca, sal y salazones en las ciudades fenicio-púnicas del sur de Iberia. En FERNÁNDEZ, J. y COSTA, B. (eds.). De la mar y de la tierra. Producciones y productos fenicio-púnicos. XV Jornadas de Arqueología Fenicio-púnica, Ibiza, 2000. Trabajos del Museo arqueológico de Ibiza y Formentera 47, Ibiza: 2001, pp. 9-66

GARCÍA VARGAS, E. (E.p.a) La pesca de especies pelágicas en la antigua Bética. Tercer Congreso de Historia de Andalucia. Córdoba, abril de 2001.

GARCÍA VARGAS, E. (E.p.b) Las pesquerías de la Bética durante el Imperio romano y la producción de púrpura. Symposium Internacional sobre Textiles y Tintes del Mediterráneo en Época Romana. Ibiza, 8-10 de noviembre de 2002.

GARCÍA VARGAS, E. (E.p.c) Las monedas y los peces: precios de las salazones e inflación en el mundo antiguo a través de los documentos escritos. Moneta Qua Scripta. Encuentro Peninsular de Numismatica Antigua, Osuna, 2003,

GARCÍA VARGAS, E.; FERRER ALBELDA, E. (2001a) Salsamenta y liquamina malacitanos en época imperial romana. Notas para un estudio histórico y arqueológico. En WULFF ALONSO, F., CRUZ ANDREOTTI, G. y MARTÍNEZ MAZA, C. (eds.). II Congreso Internacional de Historia de Málaga. Comercio y Comerciantes en la Historia Antigua de Málaga (siglos VIII a. C. - año 711 d. C.), Málaga: Céntro de Ediciones de la Diputación de Málaga, 2001a, pp. 573-594 
GARCíA VARGAS, E; FERRER ALBELDA, E. (2001b) Las salazones de pescado de la Gadir púnica. Estructuras de producción. Laverna, $n{ }^{\circ} 12$, 2001b, pp. 21-41

GRACIA ALONSO, F. (1981-1982) Ordenación tipológica del instrumental de pesca en bronce ibero-romano. Pyrenae 17-18, 1981-1982, pp. 315-328.

HANSON, K. C. (1997; 1999) The Galilean Fishing Economy and the Jesus Tradition. Biblical Theology Bulletin, $n^{0} 27,1997$, pp. 99-111. [también en línea]: $<$ http//wwww.stolaf.edu/people/kchanson/fishing.html>, 1999 [consulta $7 / 02 / 01]$

LAGÓSTENA BARRIOS, L. La producción de salsas y conservas de pescado en la Hispania romana (II a. C. - VI d.C.). Barcelona: Collecció Instrumenta 11, Universidad de Barcelona

LEQUÉMENT, R. (1980) Deux inscriptions peintés sur ampres de Bétique à Alesia. Revue Archéologique de l'Est et du Centre-Est, XXXI, 1980, pp. 256-259.

LIOU, B. y RODRÍGUEZ ALMEIDA, E. (2000) Les inscriptions peintes des amphores du pecio Gandolfo (Almeria). MEFRA : Mélanges de I'École Française de Rome. Antiquité, 112, 2000, pp. 7-25.

LUZÓN NOGUÉ, J. Maª (1988) Los hippoi gaditanos. Actas del Congreso Internacional sobre el Estrecho de Gibraltar. Ceuta, 1987. Madrid: U.N. E. D., 1988, pp. $445-458$

MARTÍNEZ MAGANTO, J. (1992) Las técnicas de pesca en la Antigüedad y sus implicaciones en el abastecimiento de las industrias de salazón. CuPAUAM: Cuadernos de Prehistoria y Arqueología de la Universidad Autónoma de Madrid, n ${ }^{\circ}$ 19, 1992, p. 219-244

MARTÍNEZ MAGANTO, J. (2001) Inscripciones sobre ánforas de salazón: interpretación sobre la estructura y significación comercial de los tituli picti. Actas del Congreso Internacional Ex Baetica Amphorae. Conservas, aceite y vino de la Bética en el Imperio Romano. Sevilla-Écija, 1998. Écija: Editorial Gráficas Sol, v 4, 2001, pp. 1221-2129

MASTROMARCO, G. (1998) La pesca del tonno nella Grecia antica: dalla realta quotidiana alla metafora poetica. Rivista di Cultura Classica e Medioevale, $\mathrm{n}^{0}$ 1-2, 1998, pp. 229-236.

MEDEROS, A. Y ESCRIBANO, G. (1999) Pesquerías gaditanas en el litoral atlántico norteafricano. RSF: Rivista di Studi Fenici, 1999, pp. 37-57

MERINO, J. Ma. (1990) Sobre algunas técnicas pesqueras tradicionales vascas. Munibe, $n^{\circ} 42,1990$, pp. 413-422

MORALES MUÑIZ, A. y ROSELLÓ IZOUIERDO, E. (1988) La riqueza del Estrecho de Gibraltar como inductor potencial del proceso de colonización de la Península Ibérica. Actas del Congreso Internacional sobre el Estrecho de Gibraltar. Ceuta, 1987. Madrid: U.N. E. D., 1988, pp. 447-457

MORENO PÁRAMO, A. y ABAD CASAL, L. (1978) Aportaciones al estudio de la pesca en la Antigüedad. Habis, $n^{\circ} 2$, 1978, pp. 209-221

OTTE, E. (1982) El comercio exterior andaluz a fines de la Edad Media. II Coloquio de Historia Medieval Andaluza. Sevilla: 1982, pp. 193-240.

PÉKARY, I. (1999) Repertoriun der hellenistischen und römischen Schiffsdaerstellungen. Munster: Boreas, Beiheft 8, 1999.
PONSICH, M. y TARRADELL, M. (1965) Garum et industries antiques de salaison dans la Meditérranée occidentale. Paris: Presses Universitaires de France, 1965

PURCELL, N. (1995) Eating fish. The paradoxes of seafood. En WILLKINS, J. HARVEY, D. y DOBSON, M. Food in Antiquity. Exeter: University of Exeter Press, 1995, pp. 132-149

RAVAZZA, N. (2000) L'ultima muciara. Trapani: Giuseppe Maurici Editori, pp. 49-50.

RIBEIRO, M. (1970) Anzóis de Tróia. Subsidios para o estudo da pesca no período lusitano-romano. AP: O Arqueólogo portugués. Série II, v. 4, 1970, pp. 221236.

ROBERT, L. (1995) Pêcheurs de Parion. Hellenica, n 10, 1995, pp. 80-94.

RODRÍGUEZ SANTANA, C. G. (1999) La pesca y la explotación marina y fluvial. En AUBET, Ma . E., CARMONA, P., CURIÁ, E., DELGADO, A., FERNÁNDEZ CANTOS, A. y PÁRRAGA, M. Cerro del Villar I. El asentamiento fenicio en la desembocadura del río Guadalhorce y su interacción con el hinterland. Sevilla: Consejeria de Cultura. Junta de Andalucia, pp. 320-324

ROSELLÓ IZQUIERDO, E. (1989) Informe preliminar de la ictiofauna de Santa Pola (Alicante). Saguntum, n²2, 1989, pp. 439-445

ROSELLÓ IZQUIERDO, E. Y MORALES MUÑIZ, A. (1988) Ictiofaunas de yacimientos costeros ibéricos: patrones de agrupamiento con ayuda de técnicas multivariantes e implicaciones paleoculturales. Actas del Congreso Internacional sobre el Estrecho de Gibraltar. Ceuta, 1987. Madrid: U.N. E. D., 1987, pp. 459472

ROSELLÓ IZQUIERDO, E. Y MORALES MUÑIZ, A. (1992) Grouping patterns in Iberian ichtyoarchaeological assemblages from coastal sites. Archaeofauna, $n^{0}$ 1, pp. 11-22

ROSELLÓ IZQUIERDO, E. Y MORALES MUÑIZ, A. (1994a) The fishes. En ROSELLÓ IZQUIERDO, E. Y MORALES MUÑIZ, A. (eds.). Castillo de Doña Blanca. Archaeo-enviromental investigations in the Bay of Cádiz, Spain (750-550 B. C.). Oxford: B.A.R. Int. Ser. 593, 1994a

ROSELLÓ IZQUIERDO, E. Y MORALES MUÑIZ, A. (1994b) Castillo de Doña Blanca: Patterns of abundance in the ichtyocoecenosis of a Phoenician site from the Iberian Peninsula. Archaeofauna, n³, 1994b, pp. 131-143

ROSELLÓ IZQUIERDO, E. Y MORALES MUÑIZ, A. (1994c) Estudio arqueozoologico de la ictiofauna recuperada en la calle del Puerto $n^{\circ} 10$ (Huelva). En GARRIDO, J. P. y ORTA, E. M. (eds.). El hábitat antiguo de Huelva (períodos orientalizante y arcaico). La primera excavación arqueológica en la calle del Puerto. EAE: Excavaciones Arqueológicas en España, n 171, 1994c, pp. 329-337

SÁÑEZ REGUART, A. (1971) Diccionario histórico de las artes de la pesca nacional. Madrid, 1791

WANKEL, H. Die Inschriften von Ephesos. Teil IA. Nr. 1-47. Texte. Bonn: Rudolf Habelt Verlag GMBH.

WüLLNER, W. (1967) The Meaning of Fishers of Men. Philadelfia: New Testament Library, 1967 